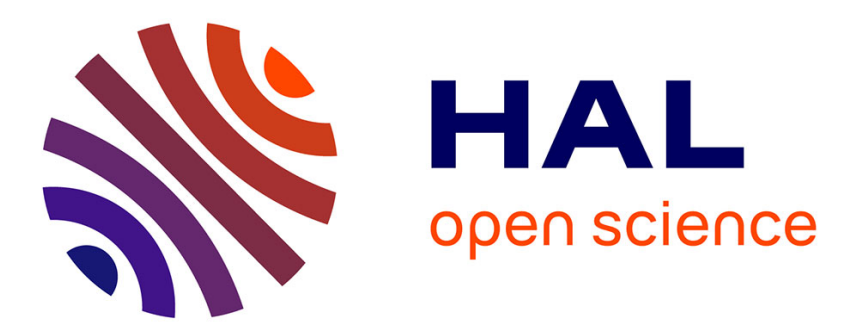

\title{
Designing high entropy superalloys for elevated temperature application
}

Yung-Ta Chen, Yao-Jen Chang, Hideyuki Murakami, Stéphane Gorsse, An-Chou Yeh

\section{- To cite this version:}

Yung-Ta Chen, Yao-Jen Chang, Hideyuki Murakami, Stéphane Gorsse, An-Chou Yeh. Designing high entropy superalloys for elevated temperature application. Scripta Materialia, 2020, 187, pp.177-182. 10.1016/j.scriptamat.2020.06.002 . hal-02886263

\section{HAL Id: hal-02886263 https://hal.science/hal-02886263}

Submitted on 27 Nov 2020

HAL is a multi-disciplinary open access archive for the deposit and dissemination of scientific research documents, whether they are published or not. The documents may come from teaching and research institutions in France or abroad, or from public or private research centers.
L'archive ouverte pluridisciplinaire HAL, est destinée au dépôt et à la diffusion de documents scientifiques de niveau recherche, publiés ou non, émanant des établissements d'enseignement et de recherche français ou étrangers, des laboratoires publics ou privés. 


\title{
Designing high entropy superalloys for elevated temperature application
}

Yung-Ta Chen ${ }^{\text {a, b }}$, Yao-Jen Chang ${ }^{\text {a, c }}$, Hideyuki Murakami ${ }^{\text {b, d }}$, Stéphane Gorsse ${ }^{\text {a, e }}$, An-Chou Yeh ${ }^{\text {a, } c^{*}}$

${ }^{a}$ Department of Materials Science and Engineering, National Tsing Hua University, 101, Sec. 2, Kuang-Fu Road, Hsinchu, 30013, Taiwan, R. O. C.

${ }^{\mathrm{b}}$ Research Center for Structural Materials, National Institute for Materials Science, 1-2-1 Sengen, Tsukuba, 305-0047, Japan.

${ }^{c}$ High Entropy Materials Center, National Tsing Hua University, 101, Sec. 2, Kuang-Fu Road, Hsinchu, 30013, Taiwan, R. O. C.

${ }^{\mathrm{d}}$ Department of Nanoscience and Nanoengineering, Waseda University, 3-4-1 Okubo, Shinjuku Tokyo, 169-8555, Japan.

${ }^{\mathrm{e}}$ CNRS, Univ. Bordeaux, Bordeaux INP, ICMCB, UMR 5026, F-33600, Pessac, France

*corresponding author: yehac@mx.nthu.edu.tw

\begin{abstract}
In the context of cast alloy development for high temperature applications, high entropy superalloys (HESA) have exhibited superior cost specific tensile strength than that of superalloys such as CM247LC. Compositions of HESA are distinctively different from those of cast superalloys with higher contents of $\mathrm{Fe}$ and $\mathrm{Ti}$, making HESA cheaper and lighter. Comparing to superalloys, although HESA has adopted the template of FCC-structured $(\gamma)$ matrix and coherent $\mathrm{L}_{2}$-structured $\left(\gamma^{\prime}\right)$ precipitates, $\gamma^{\prime}$ is enriched with solutes with higher intrinsic strength, rendering positive lattice misfit, and the high entropy $\gamma$ matrix may have attributed a good combination of strength and ductility.
\end{abstract}

Keywords: high entropy superalloys; superalloys; cost performance; high temperature properties

Superalloys are important materials for gas turbine engines in aerospace and energy industries [1]. Since the homologous temperature of superalloys has already reached the limit, efforts on alloy development have focused on improving the cost-performance by reducing the use of expensive elements such as rhenium (Re) [2]. For example, CMSX-8 [2] was developed as a more economical version of CMSX-4, which has been widely used in industry, and with respect to the cost specific tensile 
strength, the advantage of CMSX-8 over that of CMSX-4 was about 1.6 times. However, the Ni-based system constrains the composition design space for reduction in cost and density. To search for better cost-performance alloys, High Entropy Alloy (HEA) allows the exploitation of vast composition space [3-8], among different types of HEAs [9], Refractory High Entropy Alloys (RHEAs) possess high melting points and are promising structural materials, however, the development of RHEAs has yet to reach high-temperature oxidation resistance and a balance between high-temperature strength and room temperature ductility $[6,10]$, on the other hand, 3d-TM HEAs possess the best specific strength and appears to be the most promising HEA for structural application [9]. The most well-known 3d-TM HEA is $\mathrm{CoCrFeMnNi}$, although single-phase $\mathrm{CoCrFeMnNi}$ can possess attractive combination of strength and toughness from ambient to cryogenic temperatures [11], the strength of single-phase HEA is relatively weak at elevated temperatures $[6,12$, 13]. At high temperatures, diffusion driven phase transformation and creep need to be considered [1], FCC phase with lower intrinsic diffusivity than BCC phase should be the choice of structure basis for high temperature alloys [14]. Wu et al. [15] demonstrated that tensile yield strength of CoCrFeNi, CoCrMnNi, CoCrNi, CoNi and Ni dropped sharply with increasing temperature, and Otto et al. [12] found that the yield strength of $\mathrm{CoCrFeMnNi}$ was only $76 \mathrm{MPa}$ at $600{ }^{\circ} \mathrm{C}$. So, strengthening mechanisms such as solid solution strengthening, work hardening and grain refinement, are not effective at elevated temperatures.

Conventional superalloys have relied on ordered $\mathrm{Ni}_{3}\left(\mathrm{Al}\right.$, Ti)-based $\mathrm{L1}_{2}$-structured $\left(\gamma^{\prime}\right)$ precipitates to strengthen the FCC-structured $(\gamma)$ matrix. And, this type of precipitates has been introduced in HEA systems. Shun et al. [16] and Gwalani et al. [17-20] investigated $\mathrm{Al}_{0.3} \mathrm{CoCrFeNi}$, and observed precipitation of fine $\gamma^{\prime}$ precipitates in the $\gamma$ matrix; however, the $\gamma^{\prime}$ phase could only be stable up to $550{ }^{\circ} \mathrm{C}$ and was destabilized and replaced by B2-structured $(\beta)$ phase at $700{ }^{\circ} \mathrm{C}$. He et al. $[21,22]$ found that addition of $\mathrm{Al}$ and $\mathrm{Ti}$ in $\mathrm{CoCrFeNi}$ could induce formation of $\gamma^{\prime}$ phase in the $\gamma$ matrix, however, excessive addition of these two elements could promote the formation of brittle $\mathrm{L} 2{ }_{1}$-structured $(\mathrm{Ni}, \mathrm{Co})_{2} \mathrm{TiAl}$ phase. Yeh et al. [23, 24] systematically studied the $\mathrm{Al}_{\mathrm{x}} \mathrm{Co}_{1.5} \mathrm{CrFeNi}_{1.5} \mathrm{Ti}_{(0.5-\mathrm{x})}$ systems, higher Ti/Al ratio could induce higher $\gamma^{\prime}$ phase fraction and higher hardness; however, $\gamma^{\prime}$ phase was found to be unstable and could transform into brittle $\eta$ phase after prolonged exposure at 900 ${ }^{\circ} \mathrm{C}$; higher $\mathrm{Al} / \mathrm{Ti}$ ratio could promote $\beta$ phase formation instead. Daoud and Manzoni et al. [25-29] investigated a similar alloy $\mathrm{AlCo}_{2.5} \mathrm{Cr}_{0.8} \mathrm{Fe}_{1.5} \mathrm{Ni}_{3.6} \mathrm{Ti}_{0.6}$, which contained a $\gamma$ matrix with $46 \%$ of $\gamma^{\prime}$ phase and $5 \%$ of $\beta$ phase by volumes; its yield strength at $750{ }^{\circ} \mathrm{C}$ was $473 \mathrm{MPa}$, although this value appeared to surpass those of solid solution 
strengthened type superalloys such as $800 \mathrm{H}$ and Inconel617, it was still weaker than more advanced superalloys such as CM247LC [30], this was mainly due to relatively low fractions and low solvus of $\gamma^{\prime}$ phase. During the course of developing wrought HEA [31, 32], low $\gamma^{\prime}$ solvus had promoted chemical instability at the front of mobile grain boundaries and resulted the formation of cellular $\gamma-\gamma^{\prime}$ precipitates at grain boundaries during thermo-mechanical processes; this could cause severe hot ductility drop at around $750{ }^{\circ} \mathrm{C}$. So, the development of HEA for high temperature application has been focused on cast type alloy to avoid hot ductility drop associated with cellular precipitation at grain boundaries.

To further increase the elevated temperature strength to compete with superalloys, both the solvus and fractions of the $\gamma^{\prime}$ phase in HEA need to be increased; however, the volume fractions and solvus temperature of the $\gamma^{\prime}$ phase could be restricted by the increase in entropy of the system within the composition range of 5.0 at. $\% \leq \mathrm{x} \leq 35.0$ at. \% [5, 6]. To break through this restriction, alloy design has been shifted to Ni-rich HEA with $\mathrm{Ni}$ content beyond 35 at. $\%[5,6]$. CALPHAD prediction indicates that an increase in $\mathrm{Ni}$ content beyond 35 at $\%$ could allow further adjustment in the composition to increase the thermal stability of $\gamma$ matrix and $\gamma^{\prime}$ precipitates, Figure 1(a) and 1(b). Furthermore, the configurational entropy of the nominal composition can still meet the broader definition of HEA, i.e. $\left|\Delta \mathrm{S}_{\text {conf. }}\right|>1.5 \mathrm{R}$, where $\mathrm{R}$ is the universal gas constant. So, the development of Ni-rich HEA has taken the advantage of a broader definition of HEA in order to further expand the alloy design space, as shown in Figure 2(a). Since the microstructure of Ni-rich HEA with $\gamma$ matrix and $\gamma^{\prime}$ precipitates resembles that of advanced superalloys, the name "High Entropy Superalloys (HESA)" has been given to this class of materials [23, 33-36].

In the context of cast alloys, selected compositions of HESA, i.e. HESA-1 [33], HESA-2 [33] and HESA-3 [34] are shown in Table I. Compositions of HESA and traditional superalloys evolved from different origins; superalloys were designed from the Ni-based corner of the multidimensional phase diagram, and HESA was designed from the high entropy compositions near center of the same phase diagram. Although compositions of superalloys and HESA appeared to converge at the mid-point between the center and the corner of the phase diagram, HESA had taken the path of lower cost and lower density with higher $\mathrm{Fe}$ and $\mathrm{Ti}$ contents than those of cast superalloys, while cast superalloys accommodated more and more refractory $\gamma$ formers up to the $5^{\text {th }}$ generation alloy [37]; to visualize the compositions difference, Figure 2(b) shows general contents of elements in 71 cast superalloys (including the latest $5^{\text {th }}$ generation alloy) $[1,37]$ and HESA $[33,34]$. Take CM247LC as example, 
it contains 0 at $\% \mathrm{Fe}$ and 0.9 at $\% \mathrm{Ti}$; HESA-3 contains 8.9 at $\% \mathrm{Fe}$ and 5.8 at $\% \mathrm{Ti}$. HESA-3 had a density of $7.96 \mathrm{~g} / \mathrm{cm}^{3}$, and its raw materials cost was $61 \%$ cheaper than that of CM247LC. The Ni contents of HESAs were all higher than 35 at. \%, and this allowed significant increase in the solvus temperature and phase fraction of $\gamma^{\prime}$ phase, Figure 1, without the formation of detrimental phases such as $\eta, \delta$, Laves, TCP phases [1]. The enhanced phase stability of HESA could further accommodate minor $\mathrm{W}$, Mo to strengthen the FCC-structured $\gamma$ matrix, and minor $\mathrm{Ta}$ or $\mathrm{Nb}$ to strengthen $\mathrm{L1}_{2}$-structured $\gamma^{\prime}$ phase in HESA-2 and HESA-3; the solvus temperatures of $\gamma^{\prime}$ phase in HESA-2 and HESA-3 were $1194{ }^{\circ} \mathrm{C}$ [33] and $1199{ }^{\circ} \mathrm{C}$ [34], respectively, similar to those of superalloys [1]. Furthermore, the fractions of $\gamma^{\prime}$ phase in HESA-2 and HESA-3 were close to 70 vol. $\%$, which is considered as the optimum fraction for high temperature strengthening in cast superalloys [1].

The excellent phase stability of HESA had been confirmed by long term isothermal ageing at temperatures from $700{ }^{\circ} \mathrm{C}$ to $1100{ }^{\circ} \mathrm{C}$ for up to 1000 hours, only $\gamma^{\prime}$ precipitates in $\gamma$ matrix could be observed without formation of detrimental intermetallic phases [33]. Furthermore, the $\gamma^{\prime}$ phase with high Ti content resulted higher anti-phase boundary (APB) energy than that of conventional superalloys [38], which could retard superdislocations and strengthen $\gamma^{\prime}$ phase, for example the APB energies of HESA-1 and superalloy CM247LC were 0.25 and $0.19 \mathrm{~J} / \mathrm{m}^{2}$, respectively [33], this had resulted higher hardness of HESA L1 $1_{2}$-structured $\gamma^{\prime}$ phase comparing to that of CM247LC measured by nano-indentation tests [33]. On the other hand, high entropy compositions in the $\gamma$ matrix of HESAs could lead to lower stacking fault energy, which could hinder dislocation cross-slip during deformation by increasing the spacing between the partial dislocations [34] and enhance the toughness by formation of twins [7, 11, 39]. By comparing to those of conventional HEAs (5.0 at. $\% \leq \mathrm{x} \leq 35.0$ at. \%), elevated temperature tensile yield strengths of HESAs were about $200 \mathrm{MPa}$ in average higher than those of reported HEAs from room temperature to $750{ }^{\circ} \mathrm{C}$ [34], and a positive temperature dependence of the yield strength of HESAs was identified due to high fractions of $\mathrm{L1}_{2}$-structured $\gamma^{\prime}$ phase. Furthermore, the creep rupture life of HESA-3 under $982{ }^{\circ} \mathrm{C}$ and $159 \mathrm{MPa}$ was 114 hours, which was similar to several first generation superalloys; the steady state creep rate of HESA-3 was competitive against CMSX-2 [40], this was attributed to strengthening from thermally stable $\gamma^{\prime}$ precipitates, low stacking fault energy of the $\gamma$ matrix, leading to a high creep activation energy of $290 \mathrm{~kJ} / \mathrm{mol}$ [34]. Due to high solute contents in $\gamma^{\prime}$ phase, lattice misfits between FCC-structured $\gamma$ matrix and $\mathrm{L1}_{2}$-structured $\gamma^{\prime}$ phase in HESA were positive, during creep at $982{ }^{\circ} \mathrm{C}, \gamma^{\prime}$ phase rafted in parallel to the applied stress direction; this is opposite to that of advanced superalloys with negative misfit 
between $\gamma$ matrix and $\gamma^{\prime}$ precipitates [1]. Furthermore, HESAs had the ability to form continuous and protective $\mathrm{Al}_{2} \mathrm{O}_{3}$ layer after high temperature exposure; the oxidation and corrosion resistances were comparable to that of CM247LC [41]. So, HESAs can possess excellent elevated temperature phase stability and surface stabilities; their high temperature strength can be comparable to those of some commercial superalloys.

The concept of HESA has led to several recent studies in exploring the strengthening contributions from $\mathrm{L1}_{2}$-structured $\gamma^{\prime}$ phase in HEAs, however, these works mostly focused on room temperature properties and have shown that this approach could be effective in increasing the tensile strength while retaining a good level of tensile ductility [29, 42-44], e.g. $\gamma^{\prime}$ precipitates strengthened $\mathrm{Al}(\mathrm{Co}, \mathrm{Fe}$, $\mathrm{Ni})_{12.3} \mathrm{Ti}$ exhibited a tensile yield strength of $1028 \mathrm{MPa}$ with an elongation up to 47.8 $\%$ [42]. On the other hand, microstructure optimization through heat treatment can also be important in order to balance strength and ductility; Zhang et al. [36] studied a Hf containing HESA $\mathrm{Al}_{0.56} \mathrm{CoCrFeNi}_{3.36} \mathrm{Ti}_{0.56} \mathrm{Hf}_{0.015}$, in as-cast condition, its ultimate tensile strength could reach $960 \mathrm{MPa}$ at $750{ }^{\circ} \mathrm{C}$ but with only $3 \%$ fracture strain; by contrast, the directional solidified form of HESA-3 subjected to post heat treatment to optimize the microstructure could possess a tensile yield strength of $855 \mathrm{MPa}$ at 750 ${ }^{\circ} \mathrm{C}$ with fracture strain greater than $20 \%$ [34]. Due to its relatively low elemental cost and density, with respect to $750{ }^{\circ} \mathrm{C}$ yield strength, HESA-3 performed better than all reported HEA data with the same testing condition and could achieve a 3 times increase in cost-specific tensile strength comparing to that of CM247LC, Fig. 3 [30, $31,34,45]$, most importantly, its tensile elongation can be 2.7 times that of CM247LC, making HESA very attractive for elevated temperature applications.

Based on the current state of the art, the development of HESA technology has combined several alloy design strategies; viewpoints of these strategies are described and discussed in the following:

\section{Utilize low cost elements such as Fe to lower down the cost of material:}

In an alloy system based on $\mathrm{Co}-\mathrm{Ni}$, although $\mathrm{Co}$ is relatively expensive, it is utilized in conventional Ni-based superalloys to stabilize the $\gamma$ matrix and also lower the stacking fault energy [1]. Co is also a common element in HEA, while HEA composition space provides the freedom to include significant fractions of cheap elements that can lower the cost. It is important to balance the cost with desired microstructure (FCC-structured $\gamma$ matrix and $\mathrm{L1}_{2}$-structured $\gamma^{\prime}$ precipitates) and sufficient phase stability. Fe is an ideal choice of cheap element serving as matrix element, which acts mainly as a substitution to $\mathrm{Ni}$ or Co in conventional 
superalloys, however, Fe is also known to destabilize $\gamma^{\prime}$ phase [46]; CALPHAD has been a useful tool to ensure that Fe-bearing HESA could retain sufficient fractions of stable $\gamma^{\prime}$ phase. Another potential issue regarding to the cost is associated with processing, HESA reported are cast alloys, and the yield of casting can be affected by alloy compositions greatly [1, 47, 48]. In advanced superalloys, the tendency to form freckles defects can be related to both the content of refractory elements and their ratios of solid-liquid partitioning, since convection caused by density difference with the mushy zone can cause nucleation of stray grains with undesired chemical compositions. Therefore, HESA with low level of refractories might exhibit good castability for complex part, thorough investigations on castability of HESA should be conducted in the future.

2. Utilize light weight elements such as $\mathrm{Al}, \mathrm{Ti}, \mathrm{Cr}$ to lower down the density:

Ni-rich HEA design space presents the freedom to utilize higher level of light elements in the system to decrease the density of the alloy. However, the contents of light elements need to be controlled carefully in order to maintain the phase stability. In traditional superalloys metallurgy, $\mathrm{Al}$ and $\mathrm{Ti}$ are strong $\gamma^{\prime}$ formers, and phase instability associated with TCP phases can be related to the degree of supersaturation of solutes in $\gamma$ matrix $[1,49]$; $\mathrm{Cr}$ also promotes detrimental intermetallic formations such as $\sigma$ [1]; CALPHAD can be an extremely useful tool in maintaining phase stability while performing alloy design for light weight. And, HESA may possess an advantage over superalloys with a higher entropy matrix to accommodate more solid solutions, hence phase stability for the $\gamma$ matrix $[33,50]$.

3. Design through elemental partitioning characteristics between $\gamma$ matrix and $\gamma^{\prime}$ precipitate:

Constituent elements in HESAs possess characteristic partitioning tendencies, e.g. $\mathrm{Al}$ and Ti partition to $\gamma^{\prime}$ precipitates and $\mathrm{Co}, \mathrm{Cr}$, Fe partition to $\gamma$ matrix, Table II. The partitioning ratios of these elements have significant meanings to the design of HESA. First of all, the degree of entropy in $\gamma$ matrix and $\gamma^{\prime}$ precipitates can be affected; the $\gamma$ matrix needs to be high entropy to utilize the beneficial effects of HEAs, and the $\gamma^{\prime}$ phase has to retain medium entropy state to possess thermal stability. This is demonstrated in Table I \& II, from HESA-0 to HESA-1, the substitution of 2.0 at $\% \mathrm{Ni}$ by 2.0 at $\%$ Ti can affect the partitioning characteristics for other elements, resulting an increase in the entropy of $\gamma$ matrix, and a decrease in the entropy for $\gamma^{\prime}$ phase, which in turn could enhance its thermal stability. Furthermore, higher Ti content in $\gamma^{\prime}$ phase can promote an increase in APB energy to further strengthen the $\gamma^{\prime}$ phase. The partitioning ratios can also affect the lattice misfit between the $\gamma$ matrix and $\gamma^{\prime}$ phase, it can influence the morphology of $\gamma^{\prime}$ 
phase and the evolution of coarsening under stress [1], HESAs developed so far all possess positive misfit, e.g. lattice misfit of HESA-3 was $0.08 \%$ at $982{ }^{\circ} \mathrm{C}$ [34]. It has been that positive misfit alloys can possess better cyclic creep resistance than negative misfit alloys [51, 52], since cyclic creep might be closer to some actual turbine engine operating conditions, HESA should be evaluated against cyclic creep in the future.

4. Design oxidation and corrosion resistances of HESAs by promoting the formation of $\mathrm{Al}_{2} \mathrm{O}_{3}$ or $\mathrm{Cr}_{2} \mathrm{O}_{3}$ layers:

Alumina and chromia are effective barriers against oxidation and corrosion, whether $\mathrm{Al}_{2} \mathrm{O}_{3}$ or $\mathrm{Cr}_{2} \mathrm{O}_{3}$ layers can be protective depends on the compactness and continuity of the external oxide layer. For the formation of protective $\mathrm{Al}_{2} \mathrm{O}_{3}$, certain level of $\mathrm{Al}$ content and $\mathrm{Al}$ activity are required, for example, HESA-2 and HESA-3 are both $\mathrm{Al}_{2} \mathrm{O}_{3}$ formers and can perform as well as advanced superalloys against oxidation [41]. On the other hand, HESA-1 possesses higher $\mathrm{Cr}$ activity and is a $\mathrm{Cr}_{2} \mathrm{O}_{3}$ former; HESA-1 can be extremely resistant against slat-coated hot corrosion [41]. The activities of $\mathrm{Al}$ and $\mathrm{Cr}$ can be influenced by constituent elements in the system, for example, Si addition can greatly enhance both the $\mathrm{Al}$ and $\mathrm{Cr}$ activity [53], so the addition of $\mathrm{Si}$ may provide further flexibility in alloy design of HESA in the future.

5. Strengthening through hierarchical microstructure development:

Recent studies have shown that composition complexity in HEAs can induce effective heterogeneous microstructure strengthening at room temperature through phase transformation pathway design [44, 54-57]. HESA may also utilize its distinct stoichiometric $\gamma^{\prime}$ compositional complexity to accommodate $\gamma$ formers in the metastable condition, this could be done by quenching process and subsequent ageing in order to induce $\gamma$ particles formation inside $\gamma^{\prime}$. Previous studies have shown that this concept could be beneficial for elevated temperature strengthening by retarding coarsening kinetics of $\gamma^{\prime}$ phase [56], and compression creep life at elevated temperature could be improved [58]. So, strengthening through hierarchical microstructures should be explored for HESA in the future, since microstructure strengthening can be an effective mean to provide further strengthening without the use of expensive heavy elements.

Comparing the tensile strength, ductility, cost, density, and surface stability between HESA-3 and CM247LC superalloy, a combined performances chart has been constructed in Figure 4. HESA-3 can outperform CM247LC superalloy in most of these aspects and may be even more useful for applications when cost, density, and ductility are more demanding than high temperature strength. Recent studies have 
shown that cast type HESA has shown potential for high temperature applications, similar approach may also apply to develop wrought HESA in the future, since the increase in $\gamma^{\prime}$ solvus can be expected to minimize the cellular structure embrittlement at grain boundaries [31]. Recently, artificial intelligence machine learning approach has been utilized to design HEA compositions and to optimize several single property $[59,60]$, the growing interest in the research field of HESA will generate more experimental data, and artificial intelligence machine learning approach can be employed in the future to develop more advanced high entropy superalloys with customized and balanced properties.

Acknowledgement

Authors would like to acknowledge funding supports from Ministry of Science and Technology (MOST) in Taiwan under Grant MOST108-2218-E-007-005, MOST109-2634-F-007-024, and MOST109-2811-E-007-500; the "High Entropy Materials Center" from The Featured Areas Research Center Program within the framework of the Higher Education Sprout Project by the Ministry of Education.

\section{References}

[1] R.C. Reed, The superalloys: fundamentals and applications, Cambridge Univ. Press(2008).

[2] J.B. Wahl, K. Harris, Superalloys Int. Symp. 2012 (2012) 179-188.

[3] J.W. Yeh, S.K. Chen, S.J. Lin, J.Y. Gan, T.S. Chin, T.T. Shun, C.H. Tsau, S.Y. Chang, Adv. Eng. Mater. 6(5) (2004) 299-303.

[4] B. Cantor, I. Chang, P. Knight, A. Vincent, Mater. Sci. Eng. A 375 (2004) 213-218.

[5] M.C. Gao, J.W. Yeh, P.K. Liaw, Y. Zhang, High-entropy alloys: fundamentals and applications, Springer(2016).

[6] D.B. Miracle, O.N. Senkov, Acta Mater. 122 (2017) 448-511.

[7] S. Gorsse, J.-P. Couzinié, D.B. Miracle, C. R. Phys. 19(8) (2018) 721-736.

[8] E.P. George, D. Raabe, R.O. Ritchie, Nat. Rev. Mater. 4(8) (2019) 515-534.

[9] S. Gorsse, D.B. Miracle, O.N. Senkov, Acta Mater. 135 (2017) 177-187.

[10] B. Gorr, F. Müller, M. Azim, H.-J. Christ, T. Müller, H. Chen, A. Kauffmann, M. Heilmaier, Oxid. Met. 88(3) (2017) 339-349.

[11] B. Gludovatz, A. Hohenwarter, D. Catoor, E.H. Chang, E.P. George, R.O. Ritchie, Science 345 (2014) 1153-1158.

[12] F. Otto, A. Dlouhý, C. Somsen, H. Bei, G. Eggeler, E.P. George, Acta Mater. 61(15) (2013) 5743-5755.

[13] A. Gali, E.P. George, Intermetallics 39 (2013) 74-78.

[14] H. Schober, W. Petry, J. Trampenau, J. Condens. Matter Phys. 4(47) (1992) 9321. 
[15] Z. Wu, H. Bei, G.M. Pharr, E.P. George, Acta Mater. 81 (2014) 428-441.

[16] T.-T. Shun, Y.-C. Du, J. Alloys Compd. 479(1-2) (2009) 157-160.

[17] B. Gwalani, V. Soni, D. Choudhuri, M. Lee, J. Hwang, S. Nam, H. Ryu, S. Hong, R. Banerjee, Scr. Mater. 123 (2016) 130-134.

[18] B. Gwalani, V. Soni, M. Lee, S. Mantri, Y. Ren, R. Banerjee, Mater. Des. 121 (2017) 254-260.

[19] B. Gwalani, S. Gorsse, D. Choudhuri, M. Styles, Y. Zheng, R.S. Mishra, R. Banerjee, Acta Mater. 153 (2018) 169-185.

[20] B. Gwalani, S. Gorsse, D. Choudhuri, Y. Zheng, R.S. Mishra, R. Banerjee, Scr. Mater. 162 (2019) 18-23.

[21] J. He, H. Wang, H. Huang, X. Xu, M. Chen, Y. Wu, X. Liu, T. Nieh, K. An, Z. Lu, Acta Mater. 102 (2016) 187-196.

[22] J. He, H. Wang, Y. Wu, X. Liu, H. Mao, T. Nieh, Z. Lu, Intermetallics 79 (2016) 41-52.

[23] A.C. Yeh, T.K. Tsao, Y.J. Chang, K.C. Chang, J.W. Yeh, M.S. Chiou, S.R. Jian, C.M. Kuo, W.R. Wang, H. Murakami, Int. J. Metall. Mater. 1 (2015) 107.

[24] Y.-J. Chang, A.-C. Yeh, J. Alloys Compd. 653 (2015) 379-385.

[25] H. Daoud, A. Manzoni, R. Völkl, N. Wanderka, U. Glatzel, JOM 65(12) (2013) 1805-1814.

[26] A. Manzoni, H. Daoud, S. Mondal, S. Van Smaalen, R. Völkl, U. Glatzel, N. Wanderka, J. Alloys Compd. 552 (2013) 430-436.

[27] H. Daoud, A. Manzoni, N. Wanderka, U. Glatzel, JOM 67(10) (2015) 2271-2277.

[28] A.M. Manzoni, S. Singh, H.M. Daoud, R. Popp, R. Völkl, U. Glatzel, N. Wanderka, Entropy 18(4) (2016) 104.

[29] A.M. Manzoni, U. Glatzel, Mater. Charact. 147 (2019) 512-532.

[30] K. Harris, G. Erickson, R. Schwer, Suepralloys Int. Symp. 1984 (1984) 221-230.

[31] Y.-J. Chang, A.-C. Yeh, Mater. Chem. Phys. 210 (2018) 111-119.

[32] C.-M. Kuo, C.-W. Tsai, Mater. Chem. Phys. 210 (2018) 103-110.

[33] T.K. Tsao, A.C. Yeh, C.M. Kuo, H. Murakami, Adv. Eng. Mater. 19(1) (2017) 1-8.

[34] T.K. Tsao, A.C. Yeh, C.M. Kuo, K. Kakehi, H. Murakami, J.W. Yeh, S.R. Jian, Sci. Rep. 7(1) (2017) 12658.

[35] A.C. Yeh, T.K. Tsao, U.S. Patent No. 10,472,702 B2 (2019).

[36] L. Zhang, Y. Zhou, X. Jin, X. Du, B. Li, Scr. Mater. 146 (2018) 226-230.

[37] K. Kawagishi, A.C. Yeh, T. Yokokawa, T. Kobayashi, Y. Koizumi, H. Harada, Superalloys Int. Symp. 2012 (2012) 9-13.

[38] M. Chandran, S. Sondhi, Model. Simul. Mater. Sc. 19(2) (2011) 025008.

[39] G. Laplanche, A. Kostka, O. Horst, G. Eggeler, E. George, Acta Mater. 118 (2016) 152-163. 
[40] H. Rouault-Rogez, M. Dupeux, M. Ignat, Acta Mater. 42(9) (1994) 3137-3148.

[41] T.K. Tsao, A.C. Yeh, C.M. Kuo, H. Murakami, Entropy 18(2) (2016) 62.

[42] T. Yang, Y. Zhao, Y. Tong, Z. Jiao, J. Wei, J. Cai, X. Han, D. Chen, A. Hu, J. Kai, Science 362(6417) (2018) 933-937.

[43] Y.-J. Liang, L. Wang, Y. Wen, B. Cheng, Q. Wu, T. Cao, Q. Xiao, Y. Xue, G. Sha, Y. Wang, Nat. Commun. 9(1) (2018) 4063.

[44] E. Ma, X. Wu, Nat. Commun. 10(1) (2019) 1-10.

[45] S. Haas, A.M. Manzoni, F. Krieg, U. Glatzel, Entropy 21(2) (2019) 169.

[46] M. Durand-Charre, The microstructure of superalloys, (1997).

[47] R. Reed, T. Tao, N. Warnken, Acta Mater. 57(19) (2009) 5898-5913.

[48] S. Tin, T. Pollock, J. Mater. Sci. 39(24) (2004) 7199-7205.

[49] F. Long, Y. Yoo, C. Jo, S. Seo, Y. Song, T. Jin, Z. Hu, Mater. Sci. Eng. A 527(1-2) (2009) 361-369.

[50] M. Detrois, P.D. Jablonski, S. Antonov, S. Li, Y. Ren, S. Tin, J.A. Hawk, J. Alloys Compd. 792 (2019) 550-560.

[51] R. Giraud, J. Cormier, Z. Hervier, D. Bertheau, K. Harris, J. Wahl, X. Milhet, J. Mendez, A. Organista, Superalloys Int. Symp. 2012 (2012) 265-274.

[52] J. Cormier, Superalloys Int. Symp. 2016 (2016) 383-394.

[53] S. Wang, Y. Wu, C. Ni, Y. Niu, Corros. Sci. 51(3) (2009) 511-517.

[54] Z. Li, K.G. Pradeep, Y. Deng, D. Raabe, C.C. Tasan, Nature 534(7606) (2016) 227-230.

[55] T. Yang, Y.L. Zhao, Y. Tong, Z.B. Jiao, J. Wei, J.X. Cai, X.D. Han, D. Chen, A. Hu, J.J. Kai, K. Lu, Y. Liu, C.T. Liu, Science 362(6417) (2018) 933-937.

[56] S. Meher, L. Aagesen, M. Carroll, T. Pollock, L. Carroll, Sci. Adv. 4(11) (2018) eaao6051.

[57] S. Dasari, B. Gwalani, A. Jagetia, V. Soni, S. Gorsse, R. Banerjee, Sci. Rep. 10(1) (2020) 1-15.

[58] T.M. Smith, Y. Rao, Y. Wang, M. Ghazisaeidi, M.J. Mills, Acta Mater. 141 (2017) 261-272.

[59] Y.-J. Chang, C.-Y. Jui, W.-J. Lee, A.-C. Yeh, JOM 71(10) (2019) 3433-3442.

[60] C. Wen, Y. Zhang, C. Wang, D. Xue, Y. Bai, S. Antonov, L. Dai, T. Lookman, Y. Su, Acta Mater. 170 (2019) 109-117. 

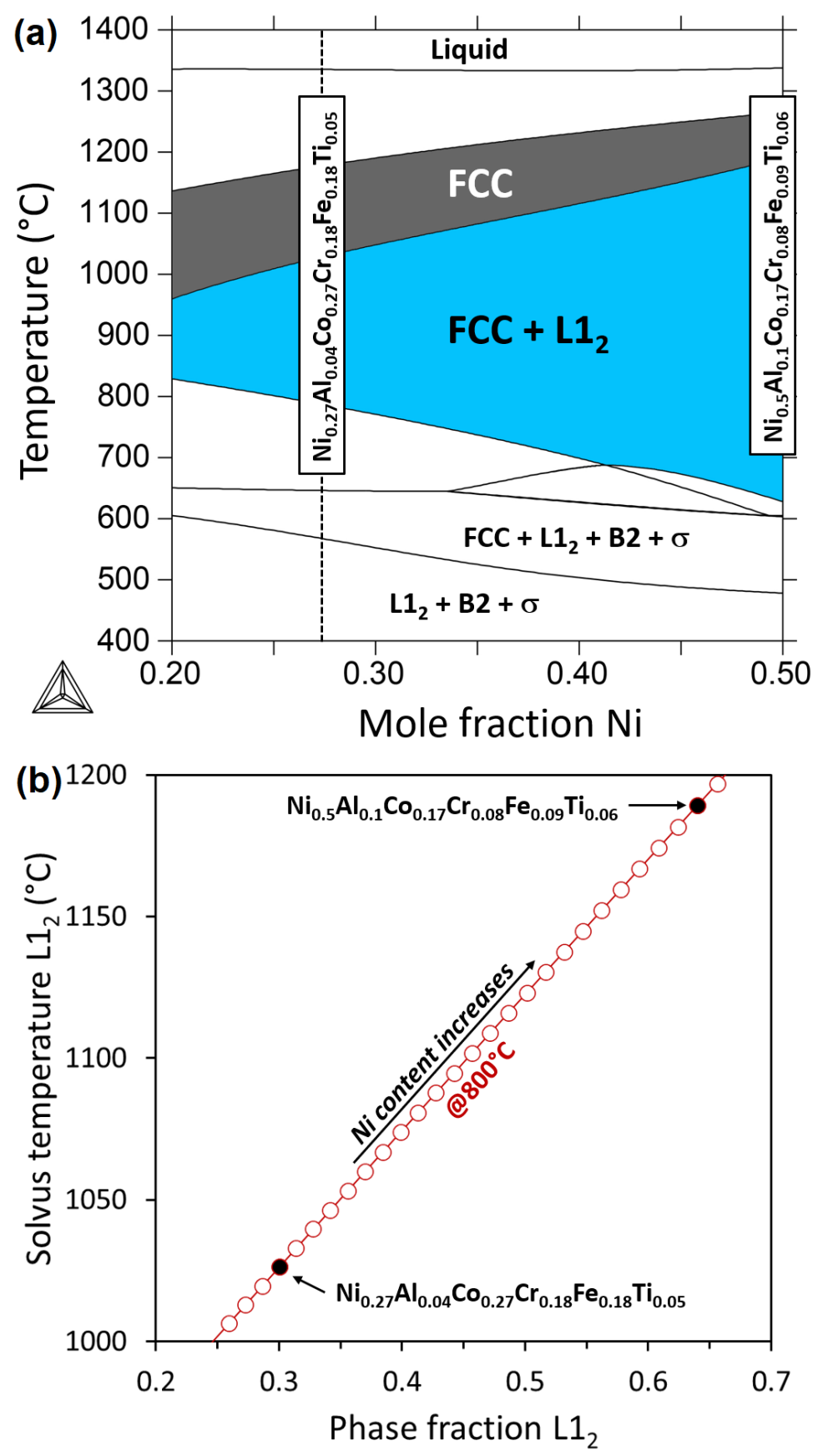

Figure 1. CALPHAD predictions for HESA development (a) isopleth section of the Al-Co-Cr-Fe-Ni-Ti senary system along the line connecting HEA(A10.2Ti0.3) and HESA-3 in Table I showing that Ni-rich HEA allows alloy design for greater FCC + $\mathrm{L}_{2}$ structure phase field, and (b) increase in solvus temperature and $\mathrm{L} 1_{2}$ equilibrium fraction at $800^{\circ} \mathrm{C}$ with $\mathrm{Ni}$ content along the same compositional trajectory as (a). 

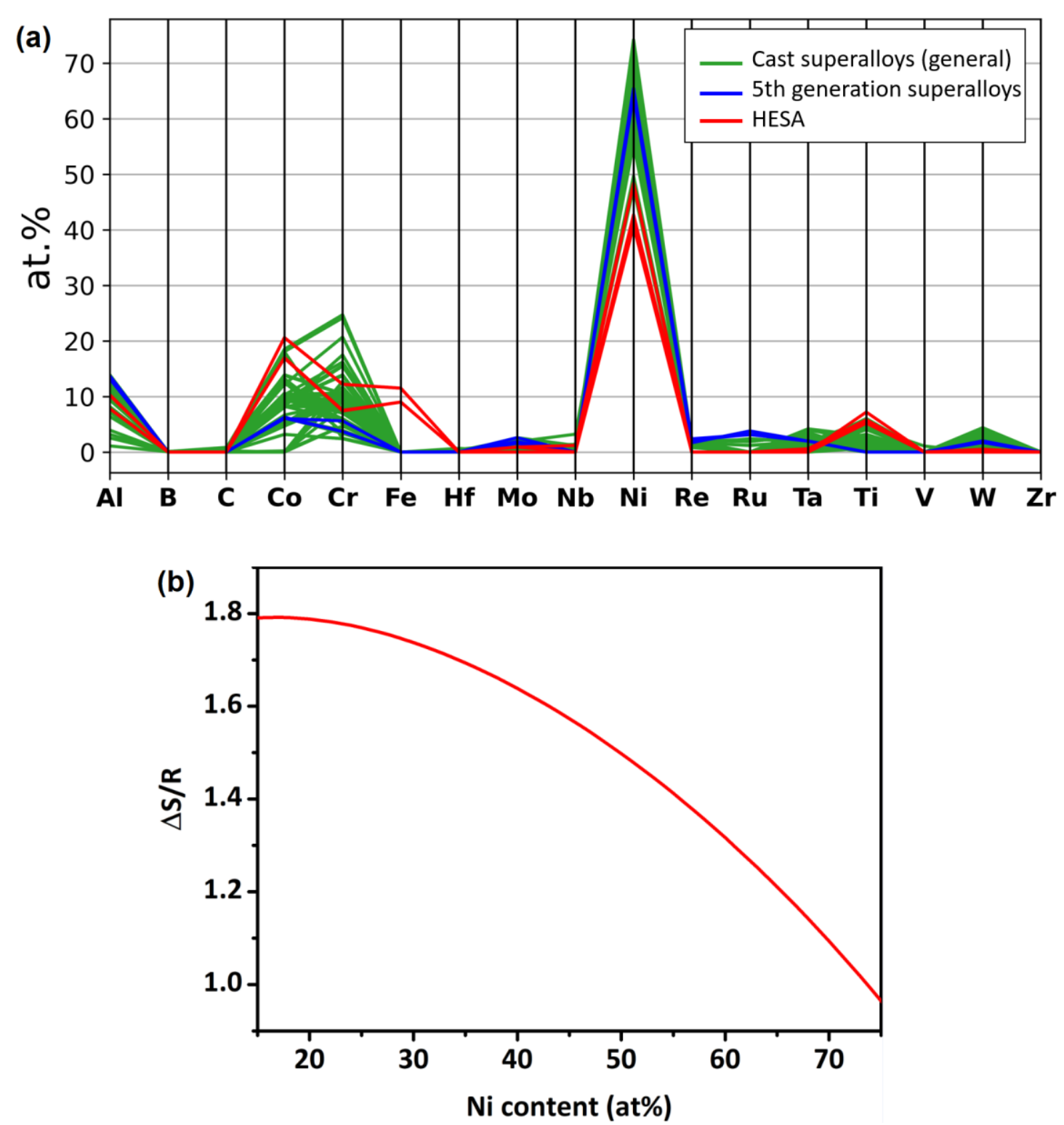

Figure 2. (a) compositions of cast superalloys (including $5^{\text {th }}$ generation superalloys) vs HESA. (b) The configurational entropy of the nominal composition can meet the broader definition of HEA $\left(\mathrm{Ni}_{\mathrm{x}}(\mathrm{AlCoCrFeTi})_{\mathrm{y}}\right)$, i.e. $\left|\Delta \mathrm{S}_{\text {conf. }}\right|>1.5 \mathrm{R}$ with Ni content greater than 35 at $\%$. 


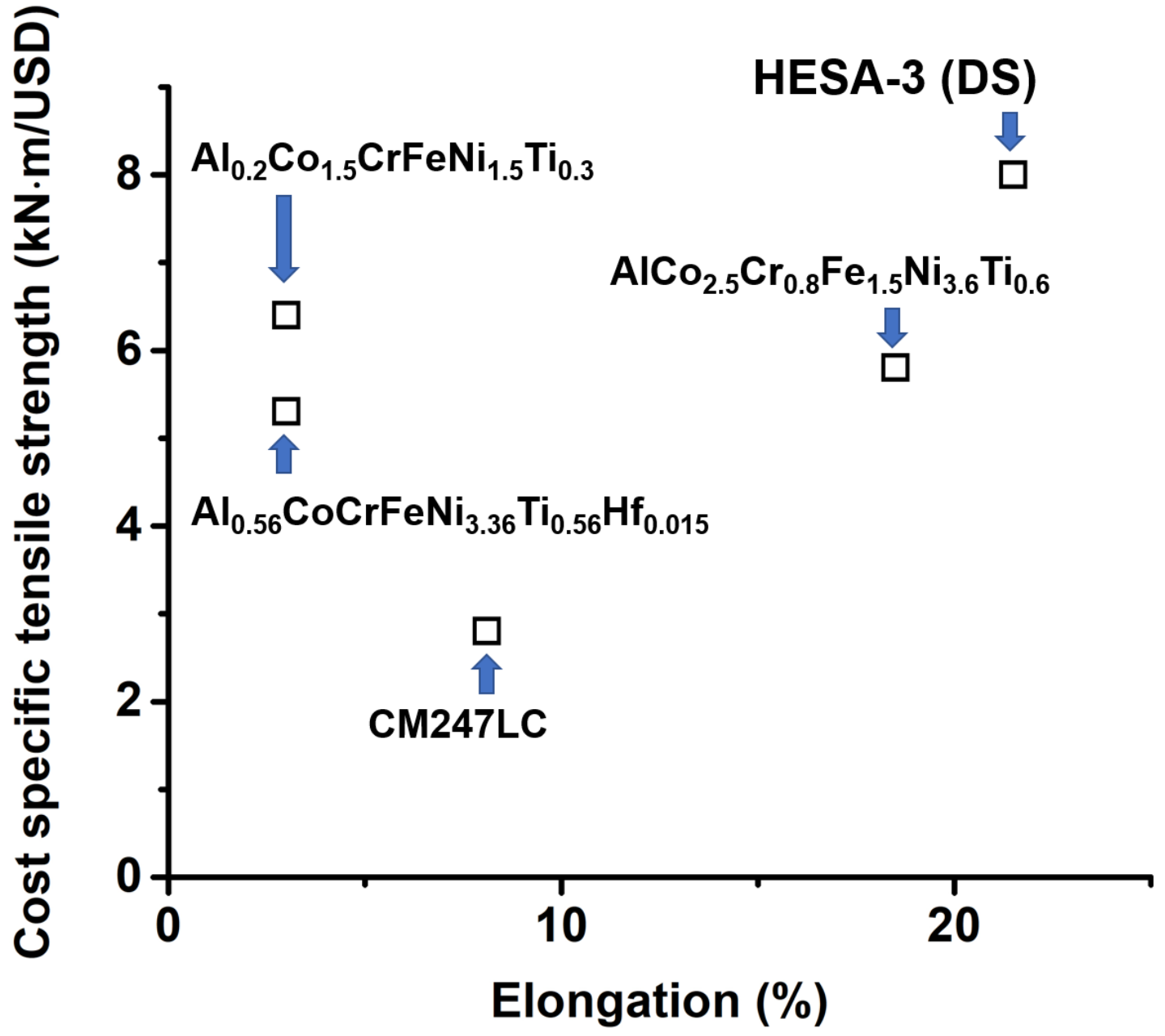

Figure $3.750{ }^{\circ} \mathrm{C}$ tensile data for cost specific tensile strength vs elongation 


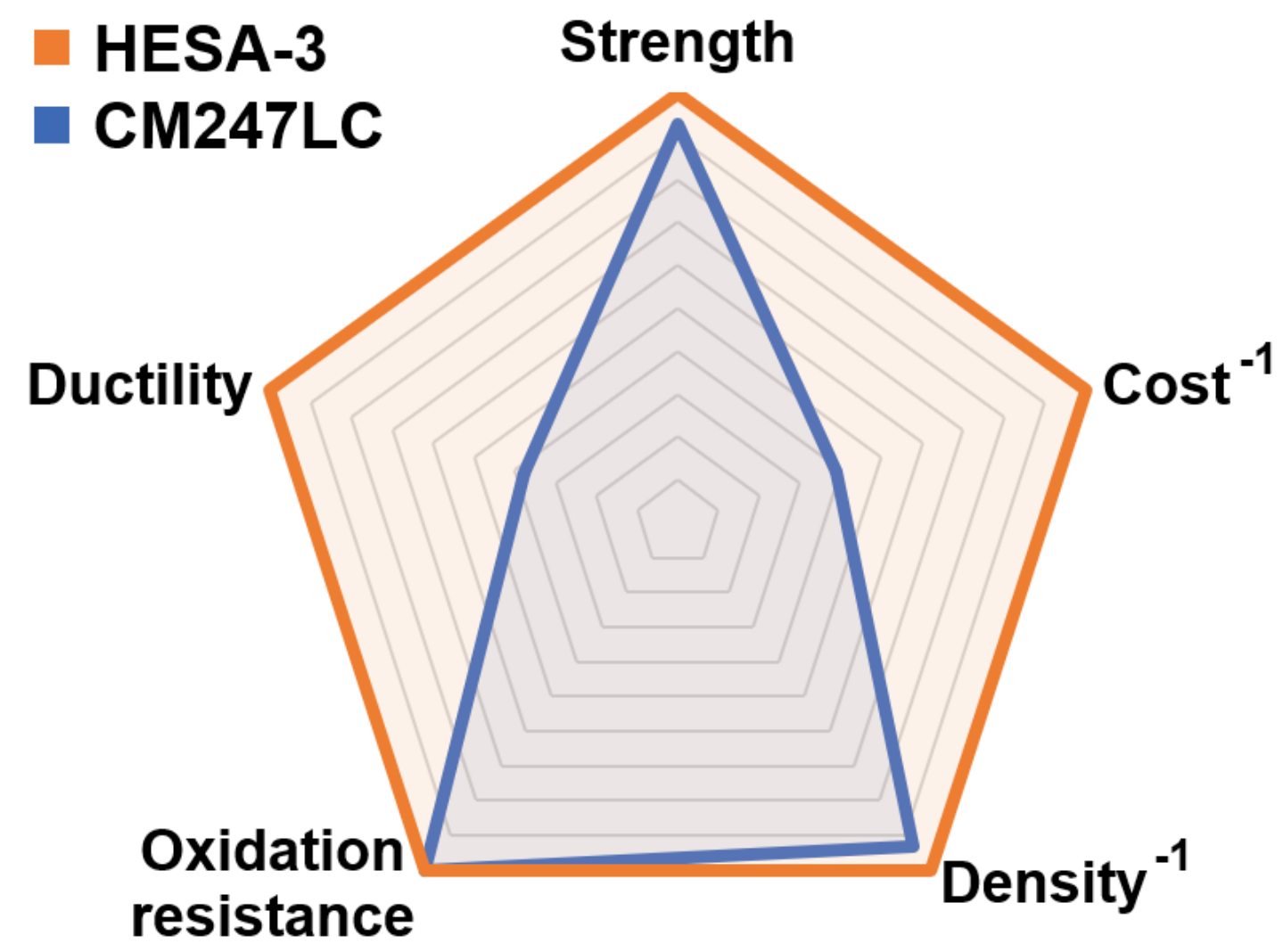

Figure 4. Combined performances and properties chart for HESA-3 vs CM247LC 
